Article

\title{
Fabrication of a Flexible Micro CO Sensor for Micro Reformer Applications
}

\section{Chi-Yuan Lee *, Chi-Chung Chang and Yi-Man Lo}

Department of Mechanical Engineering, Yuan Ze Fuel Cell Center, Yuan Ze University, Taoyuan, Taiwan; E-Mails: s975055@ mail.yzu.edu.tw (C.-C.C.); s995048@ mail.yzu.edu.tw (Y.-M.L.)

* Author to whom correspondence should be addressed; E-Mail: cylee@ saturn.yzu.edu.tw; Tel.: +886-3-4638800 ext. 2478; Fax: +886-3-4558013.

Received: 25 October 2010; in revised form: 22 November 2010 / Accepted: 29 November 2010 / Published: 30 November 2010

\begin{abstract}
Integration of a reformer and a proton exchange membrane fuel cell (PEMFC) is problematic due to the presence in the gas from the reforming process of a slight amount of carbon monoxide. Carbon monoxide poisons the catalyst of the proton exchange membrane fuel cell subsequently degrading the fuel cell performance, and necessitating the sublimation of the reaction gas before supplying to fuel cells. Based on the use of micro-electro-mechanical systems (MEMS) technology to manufacture flexible micro CO sensors, this study elucidates the relation between a micro $\mathrm{CO}$ sensor and different $\mathrm{SnO}_{2}$ thin film thicknesses. Experimental results indicate that the sensitivity increases at temperatures ranging from $100-300{ }^{\circ} \mathrm{C}$. Additionally, the best sensitivity is obtained at a specific temperature. For instance, the best sensitivity of $\mathrm{SnO}_{2}$ thin film thickness of $100 \mathrm{~nm}$ at $300{ }^{\circ} \mathrm{C}$ is $59.3 \%$. Moreover, a flexible micro $\mathrm{CO}$ sensor is embedded into a micro reformer to determine the $\mathrm{CO}$ concentration in each part of a micro reformer in the future, demonstrating the inner reaction of a micro reformer in depth and immediate detection.
\end{abstract}

Keywords: MEMS; flexible micro CO sensor; micro reformer

\section{Introduction}

Integration of a reformer and a proton exchange membrane fuel cell (PEMFC) is problematic due to the gas from the reforming process which contains a slight amount of carbon monoxide. Carbon 
monoxide poisons the catalyst of the proton exchange membrane fuel cell subsequently degrading the fuel cell performance, and necessitating the sublimation of the reaction gas before supplying it to fuel cells. Additionally, detecting extremely low concentrations of $\mathrm{CO}$ in pure $\mathrm{H}_{2}$ or $\mathrm{H}_{2}$-rich gases in a fuel cell is important. Given the well known poisoning of platinum by $\mathrm{CO}$, maintaining satisfactory performance in a PEMFC requires avoiding $\mathrm{CO}$ in the fuel gas and devising $\mathrm{CO}$ sensors that will operate under extreme conditions.

Fukuie [1] found that incorporating $\mathrm{La}_{2} \mathrm{O}_{3}$ and $\mathrm{Au}$ can successfully cause the activation of $\mathrm{CO}$ inherent in gold and make it possible to detect $\mathrm{CO}$ selectively and stably. Williams [2] fabricated a $\mathrm{CO}$ sensor using tin oxide $\left(\mathrm{SnO}_{2}\right)$, in which platinum has a lower reaction temperature, faster response time and shorter recovery time.

Horrillo [3] investigated not only how catalysts (Pt and Pd) affect tin-oxide films, but also how Pt and Pd catalysts affect films prepared by reactive sputtering and screen-printing based on an analysis of their respective roles. The catalyst particles compensate for the holes between the grains of the tin-oxide films prepared by screen-printing, subsequently increasing the stability and reproducibility of the films and achieving an excellent $\mathrm{CO}$ detection capability at low concentrations. According to their results, Pt and Pd catalysts increased the sensitivity and diminish the times of recuperation.

Habibzadeh [4] studied how $\mathrm{Sm}_{2} \mathrm{O}_{3}$ influences the sensitivity and selectivity of $\mathrm{SnO}_{2}$-based sensors for the selective detection of $\mathrm{CO} . \mathrm{Sm}_{2} \mathrm{O}_{3}$ acts as a crystal growth inhibitor and decreases $\mathrm{SnO}_{2}$ sizes. Additionally, oxygen adsorption was increased by doping $\mathrm{Sm}_{2} \mathrm{O}_{3}$, subsequently increasing the depletion of layer thickness.

Izu [5] fabricated $\mathrm{CO}$ sensor elements by connecting two cerium oxide (ceria) thick films. The cerium oxide thick film sintered at $950{ }^{\circ} \mathrm{C}$ displayed a better response for $\mathrm{CO}$ gas and lower resistance. Moreover, the connected sensor element with Pt/alumina catalyst fabricated in that study exhibited better sensitivity.

Pijolat [6] studied a samarium doped ceria (SDC) sensor, i.e., a potentiometric sensor working with an electrode dissymmetry $\mathrm{Au} / \mathrm{Pt}$. This sensor detects low $\mathrm{CO}$ concentrations in $\mathrm{H}_{2}$-rich atmosphere for PEMFC applications.

Despite various CO sensor applications [7-9], micro reformer-related applications have received less attention. The micro CO sensor based on MEMS technology is characterized by its small volume, light mass and high precision. In this study, a flexible micro $\mathrm{CO}$ sensor is embedded into a micro reformer to determine the $\mathrm{CO}$ concentration in each part of a micro reformer in the future, conferring the inner reaction of a micro reformer depth and immediate detection capability.

\section{Methodology}

By adopting a semiconductor sensor, the $\mathrm{CO}$ sensor in this study uses reductive gas and oxygen adsorption at the surface of a gas-sensitive thin film, due to the relative ease that an oxygen atom has in seizing electrons inside the material and becoming an oxygen ion after adsorbing on the surface of gas-sensitive thin film, ultimately decreasing the number of electrons inside the gas-sensitive thin film and increasing its resistance. When the surface of a gas-sensitive thin film contacts with a reductive gas, e.g., carbon monoxide, the reductive gas reacts with the oxygen ion that adsorbs on the surface of 
gas-sensitive thin film, ultimately releasing electrons to a gas-sensitive thin film and decreasing the resistance of a material as indicated by the following scheme [10]:

$$
\mathrm{CO}+1 / 2 \mathrm{O}_{2} \rightarrow \mathrm{CO}_{2}
$$

The gas-sensitive thin film in this study uses $\mathrm{SnO}_{2}$, which is characterized by its high sensitivity to hydrocarbons, stable chemical properties and high fabrication compatibility, all of which account for its high suitability in a gas-sensitive thin film. The extensive use of oxide in the $\mathrm{SnO}_{2}$ base allows $\mathrm{SnO}_{2}$ to work at a low operational temperature, as well as have a high sensitivity [10]. Gas-sensitive sensors are characterized by their sensitivity, stability, repeatability and selectivity. At an appropriate operational temperature, adsorption and desorption of oxygen occur, in which the difference in temperature leads to a difference of sensitivity. Additionally, the reaction rate increases when selecting an appropriate operational temperature, subsequently decreasing the response time between $\mathrm{SnO}_{2}$ thin film and reductive gas. The measurement results are influenced by the adsorption and desorption at the material surface. Notably, appropriately adding a catalyst can decrease the reaction temperature, as well as raise the response time, recovery time and selectivity. Obviously, a high sensitivity, quick response time and reuse are all essential features for a gas-sensitive sensor.

\section{Fabrication of Flexible Micro CO Sensors}

Figure 1 shows the fabrication of the flexible micro $\mathrm{CO}$ sensors. The first step involves rinsing stainless steel foil with Piranha etchant and controlling the temperature to remove the oxide on the surface.

Figure 1. Fabrication flowchart of a flexible micro $\mathrm{CO}$ sensor.

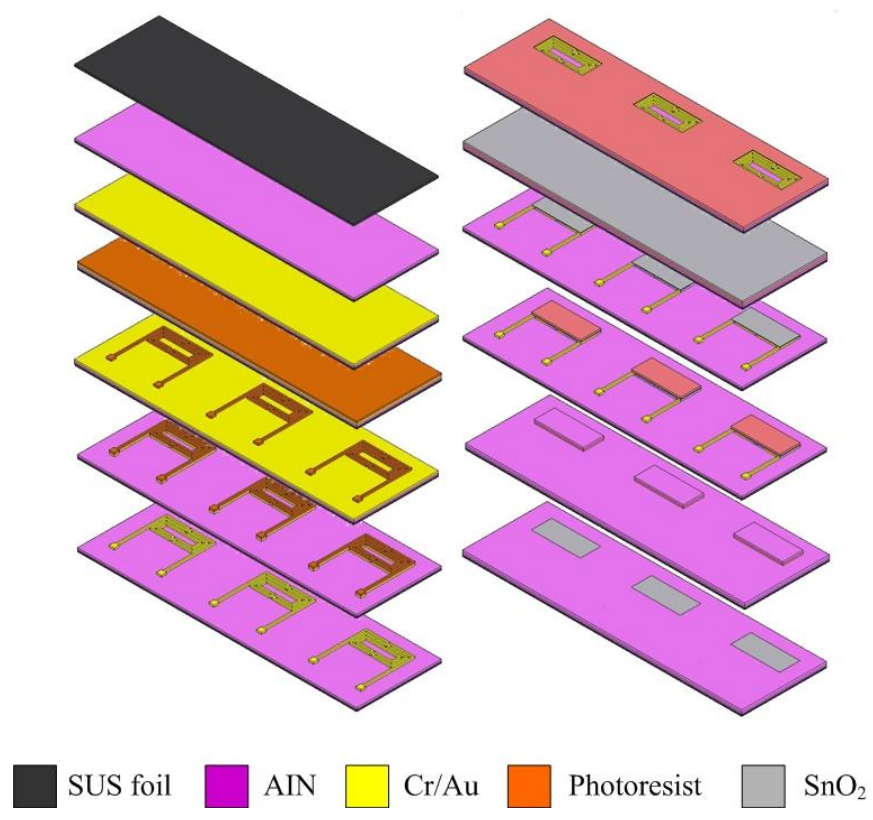

After cleaning, the stainless steel foil is soaked in acetone and placed in an ultrasonic cleaner, followed by soaking in methanol and washing with DI-water. The second step involves using RF 
sputter to sputter $10,000 \AA$ of AlN on the stainless steel foil to form the isolation layer. The third step involves using the E-beam evaporator to evaporate $400 \AA$ of chromium and 2,000 $\AA$ of gold on the aluminum nitride to be a sticking layer and electrode layer, respectively. The fourth step involves using a spin coater to coat HMDS to be the sticking layer for a photoresist, followed by coating of AZ-4620 photoresist. The fifth step involves using an aligner to transit the pattern of a photoresist, in which the developer is used to devise the required shape. The sixth step involves using etchant (Type-TFA) to etch the gold and another etchant (Cr-7T) to etch the chromium. The seventh step involves removing the photoresist. The eighth step involves coating the photoresist on stainless steel foil to be a sputtering mask, followed by transiting the pattern of photoresist and developing the required shape. The ninth step involves using RF sputter to sputter $\mathrm{SnO}_{2}$ on the stainless steel foil to become the gas sensitive layer. The tenth step involves lifting off the photoresist with stripper (Remove 1165 ) at $80{ }^{\circ} \mathrm{C}$. The eleventh step involves coating a photoresist on the stainless steel foil to be a sputtering mask, transiting the pattern of photoresist and developing the required shape. The twelfth step involves using RF sputter to sputter aluminum nitride on the stainless steel to become an isolation layer. Following soaking of the stainless steel foil in an etchant (Remove 1165) to lift off and etch aluminum nitride, the micro CO sensor is finished. Figure 2 schematically depicts a CO sensor.

Figure 2. Optical microscopy image of a micro CO sensor.

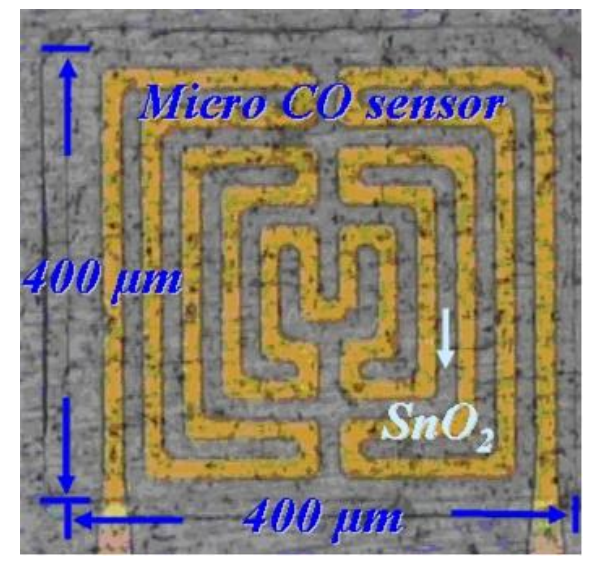

\section{Results and Discussion}

\subsection{Measurement System of a Micro CO Sensor}

Adjusting the micro $\mathrm{CO}$ sensor initially involves heating the sensitive element to a working temperature, followed by infusion with air until the resistance achieves a constant value, subsequently infusing 100, 300, 1,000 ppm of $\mathrm{CO} / \mathrm{N}_{2}$ mixing gas into the micro reformer. A mass flow controller (MFC) is used to control the flow and a NI PXI-1033 as well as a computer are used to record the resistance. Response time is determined by the curve between time and resistance by infusing air and $\mathrm{CO} / \mathrm{N}_{2}$ mixing gas. The $\mathrm{CO}$ sensor calibration system is shown in Figure 3. 
Figure 3. Calibration system of $\mathrm{CO}$ sensor.

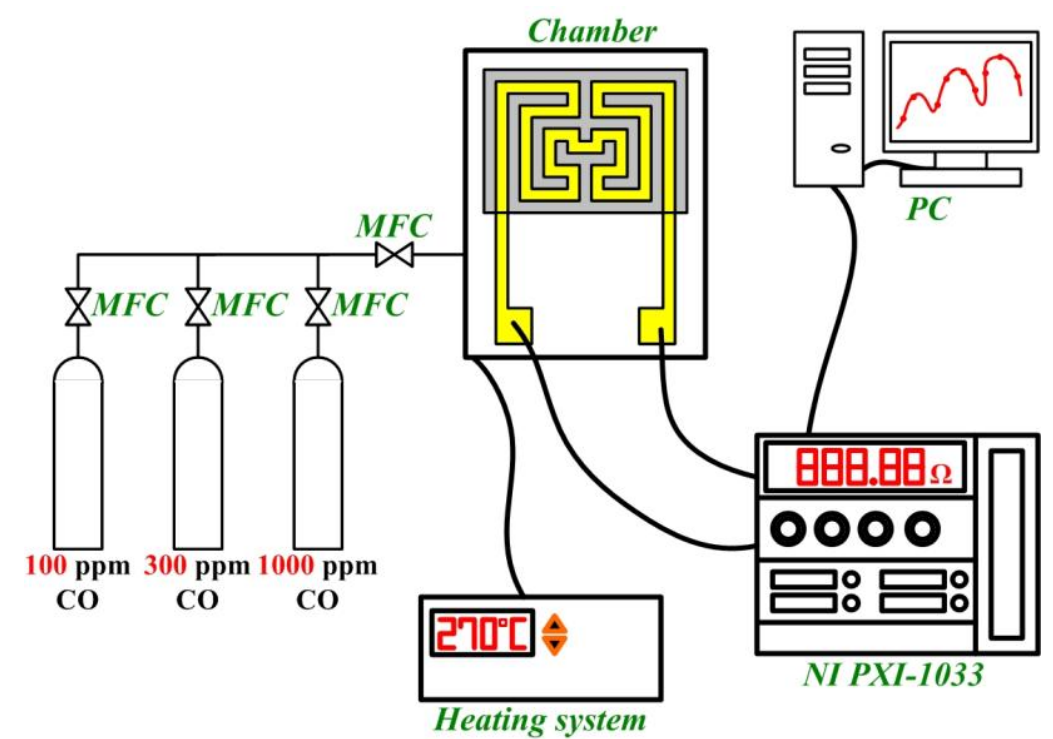

\subsection{Effect of $\mathrm{SnO}_{2}$ Thickness on Micro CO Sensor at Various Temperatures}

Figure 4 shows the relationship between operating temperature and sensitivity with different $\mathrm{SnO}_{2}$ thicknesses at $1,000 \mathrm{ppm}$ of $\mathrm{CO}$. According to this figure, the sensitivity increases with temperature at $100-300{ }^{\circ} \mathrm{C}$.

Figure 4. Relation between temperature and sensitivity for various $\mathrm{SnO}_{2}$ thin film thicknesses.

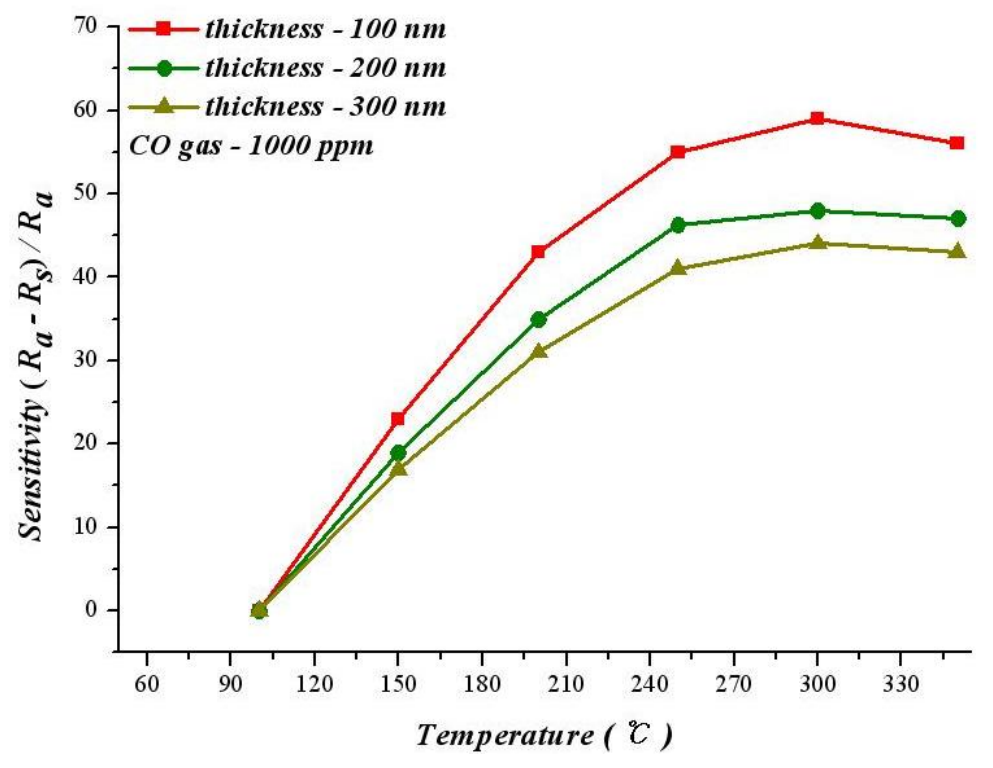

Figures 5 and 6 illustrate the atomic force microscope (AFM) photographs of the $\mathrm{SnO}_{2}$ thin film, while Figures 7 to 9 display scanning electron microscope (SEM) photographs of the $\mathrm{SnO}_{2}$ thin film. According to these figures, $100 \mathrm{~nm}$ of $\mathrm{SnO}_{2}$ thin film has a smaller grain, producing a larger surface, allowing it to adsorb more oxygen on the surface, and achieving a higher sensitivity. 
Figure 5. AFM photo of $100 \mathrm{~nm} \mathrm{SnO}_{2}$ thin film.

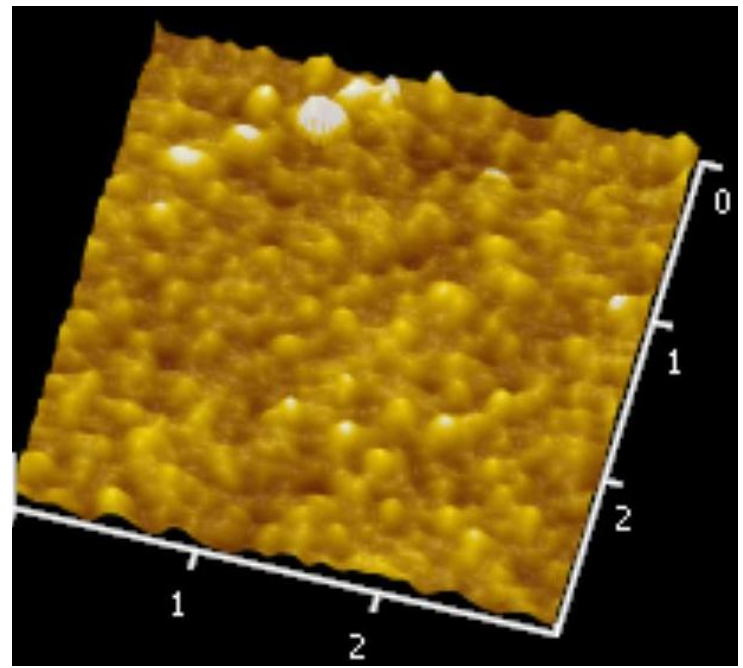

Figure 6. AFM photo of $300 \mathrm{~nm} \mathrm{SnO}_{2}$ thin film.

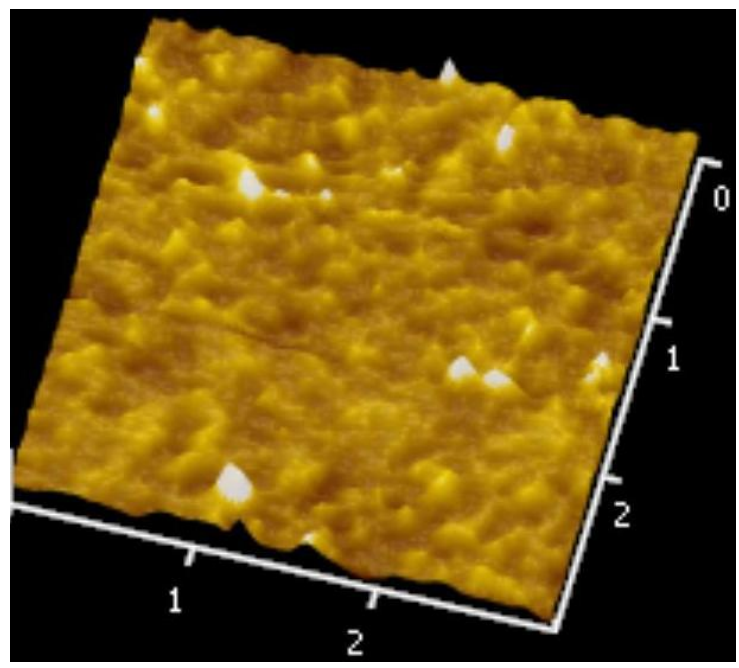

Figure 7. SEM photo of $100 \mathrm{~nm} \mathrm{SnO}_{2}$ thin film.

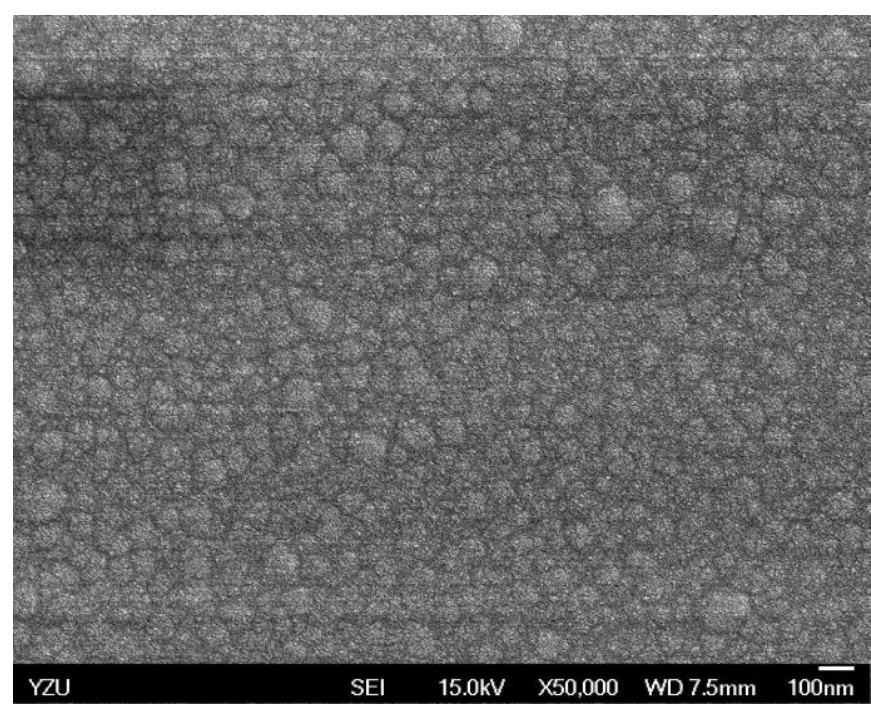


Figure 8. SEM photo of $200 \mathrm{~nm} \mathrm{SnO}_{2}$ thin film.

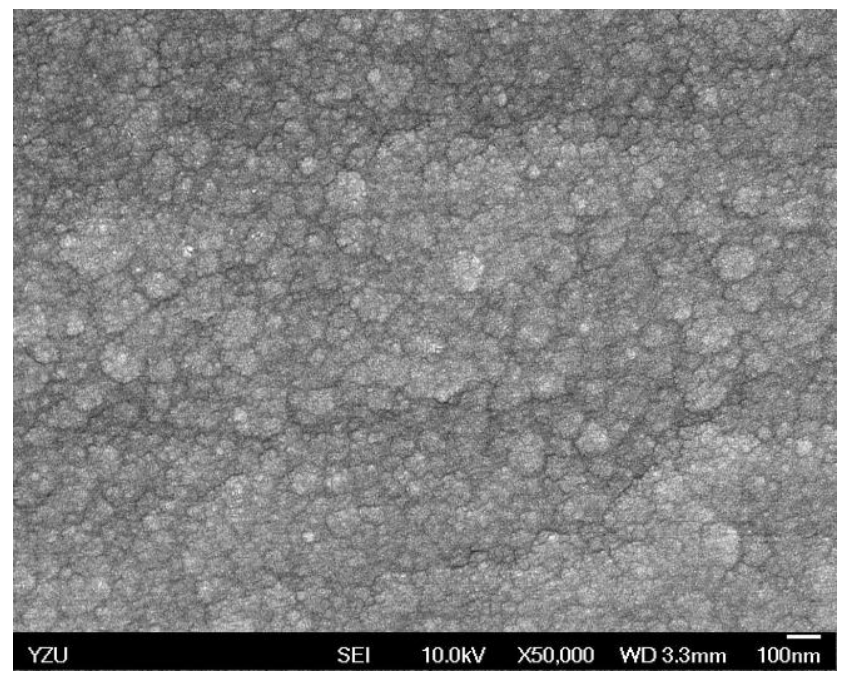

Figure 9. SEM photo of $300 \mathrm{~nm} \mathrm{SnO}_{2}$ thin film.

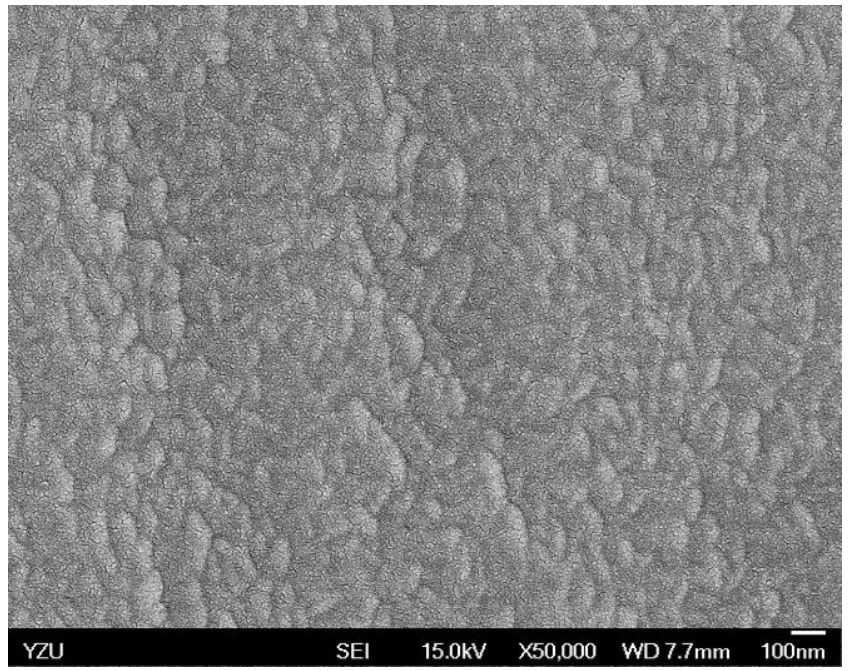

As an exothermic reaction, the adsorption reaction is unfavorable for the reaction after the temperature exceeds a critical temperature after infusing $\mathrm{CO}$. Therefore, the optimum sensitivity can be obtained at a specific temperature. Figure 4 reveals that the best sensitivity of $100 \mathrm{~nm} \mathrm{SnO}_{2}$ thin film operating at $300{ }^{\circ} \mathrm{C}$ is $59.3 \%$. However, when the thicknesses are $200 \mathrm{~nm}$ and $300 \mathrm{~nm}$, operating at $350{ }^{\circ} \mathrm{C}$ leads to best sensitivities of $48.3 \%$ and $43.5 \%$.

\subsection{Effect of $\mathrm{SnO}_{2}$ Thickness on a Micro CO Sensor at $280^{\circ} \mathrm{C}$}

When the temperature is lower than $300{ }^{\circ} \mathrm{C}$, sensitivity decreases with increasing film thickness at the same temperature. For sensitivity analysis, the adsorption of gas sensitive thin film is used to change the resistance to gas; a larger reaction area causes a greater adsorbption of oxygen ions; in addition, the resistance increases when infusing a reductive gas. Consequently, increasing the reaction area can raise the sensitivity. Figure 10 shows the diagram of sensitivity and time variation for $1,000 \mathrm{ppm}$ of $\mathrm{CO}$ at $280{ }^{\circ} \mathrm{C}$. When carbon monoxide is infused, sensitivity increases as time 
proceeds. Moreover, the rate of increasing of $100 \mathrm{~nm} \mathrm{SnO}$ thin film sensitivity is faster than that of $200 \mathrm{~nm}$ and $300 \mathrm{~nm}$ films; the response time is faster as well.

When carbon monoxide stops infusing, the recovery time of $100 \mathrm{~nm} \mathrm{SnO}_{2}$ thin film is faster than for $200 \mathrm{~nm}$ and $300 \mathrm{~nm}$ film. Hence, when carbon monoxide disappears, carbon dioxide has a different desorption ratio owing to the different thicknesses of $\mathrm{SnO}_{2}$ thin film. Moreover, $100 \mathrm{~nm}$ of $\mathrm{SnO}_{2}$ thin film has a higher recovery time because $\mathrm{CO}_{2}$ more easily desorbed, subsequently adsorbing more oxygen ions on the surface.

Figure 10. Relation between temperature and sensitivity for various $\mathrm{SnO}_{2}$ thin film thicknesses $\left(\mathrm{T}=280^{\circ} \mathrm{C}\right)$.

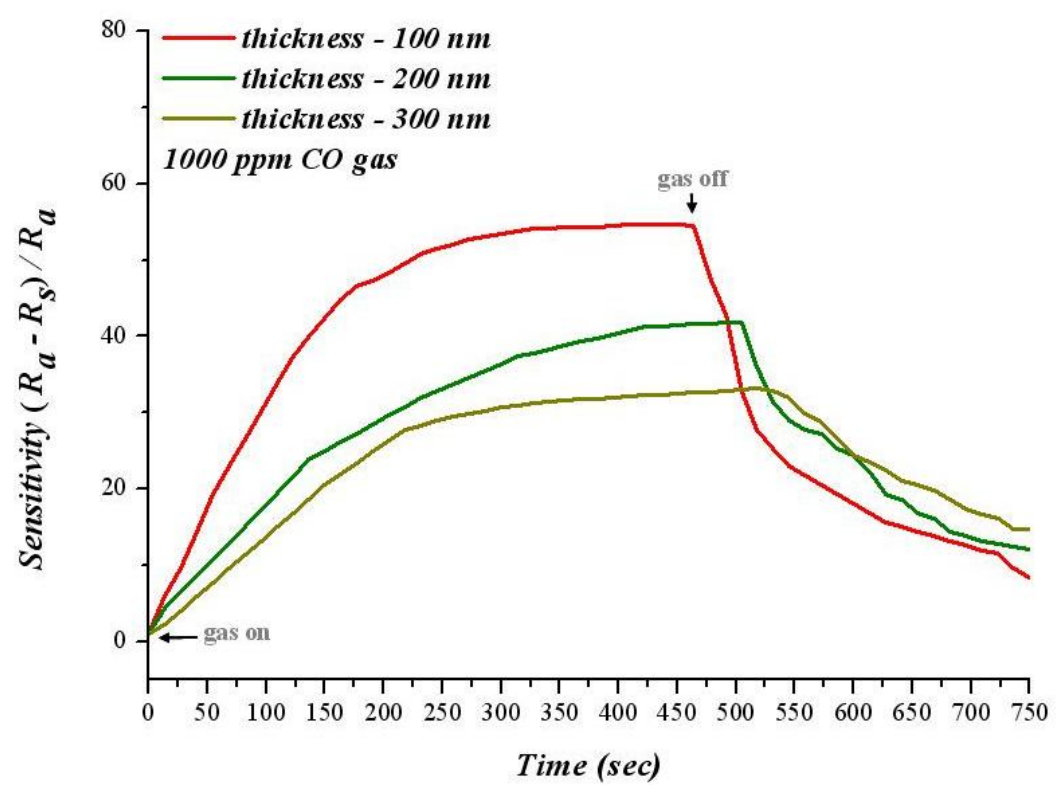

\subsection{Analysis of Reproducibility and Stability}

Reproducibility refers to the unity of output signals after successive testing. A normal gas sensor not only has a high sensitivity, but also reproducibility and stability. Figure 11 shows the relation between operating time and sensitivity for $100 \mathrm{~nm}$ of $\mathrm{SnO}_{2}$ thin film at $300{ }^{\circ} \mathrm{C}$ in $1,000 \mathrm{ppm}$ of carbon monoxide. This figure reveals that when carbon monoxide is removed, sensitivity decreases quickly. Although carbon monoxide is infused in 600 seconds, the sensitivity is not restored to the initial value. Furthermore, sensitivity decreases with increasing cycle number (when it cycles three times, sensitivity decreases from $65.3 \%$ to $39.2 \%$ ).

Sensitivity cannot remain in a steady state at $300{ }^{\circ} \mathrm{C}$. However, when the temperature is reduced to $270{ }^{\circ} \mathrm{C}$, the sensitivity has a better reproducibility and stability, as shown in Figure 12 . The sensitivity of $100 \mathrm{~nm}$ thin film can be maintained at 59.5\% at the 750th second for 1,000 ppm of CO. Thus, the sensitivity has a higher better reproducibility and stability at $270{ }^{\circ} \mathrm{C}$.

Figure 13 shows how different $\mathrm{CO}$ concentrations affect the sensitivity of $100 \mathrm{~nm} \mathrm{SnO}_{2}$ film. According to this figure, the sensitivity increases with the $\mathrm{CO}$ concentration. An increasing difference of $\mathrm{CO}$ concentration also increases the variation of sensitivity. This finding suggests that the $\mathrm{SnO}_{2}$ thin 
film has a good sensitivity for different $\mathrm{CO}$ concentrations. At different concentrations of carbon monoxide, removing carbon monoxide significantly decreases sensitivity, which remains uninfluenced by the environment. This figure also reveals that sensitivity easily becomes saturated with a decreasing concentration of carbon monoxide. However, the reaction time is not obviously shortened; it is the same due to the relation between reaction time and operating time. Although $\mathrm{SnO}_{2}$ thin film has a faster response time and best sensitivity at $300{ }^{\circ} \mathrm{C}$, the reproducibility and chronic stability are not as good. For reproducibility and chronic stability, $270{ }^{\circ} \mathrm{C}$ is a preferred operating temperature.

Figure 11. Analysis of reproducibility and stability $\left(\mathrm{T}=300^{\circ} \mathrm{C}\right)$.

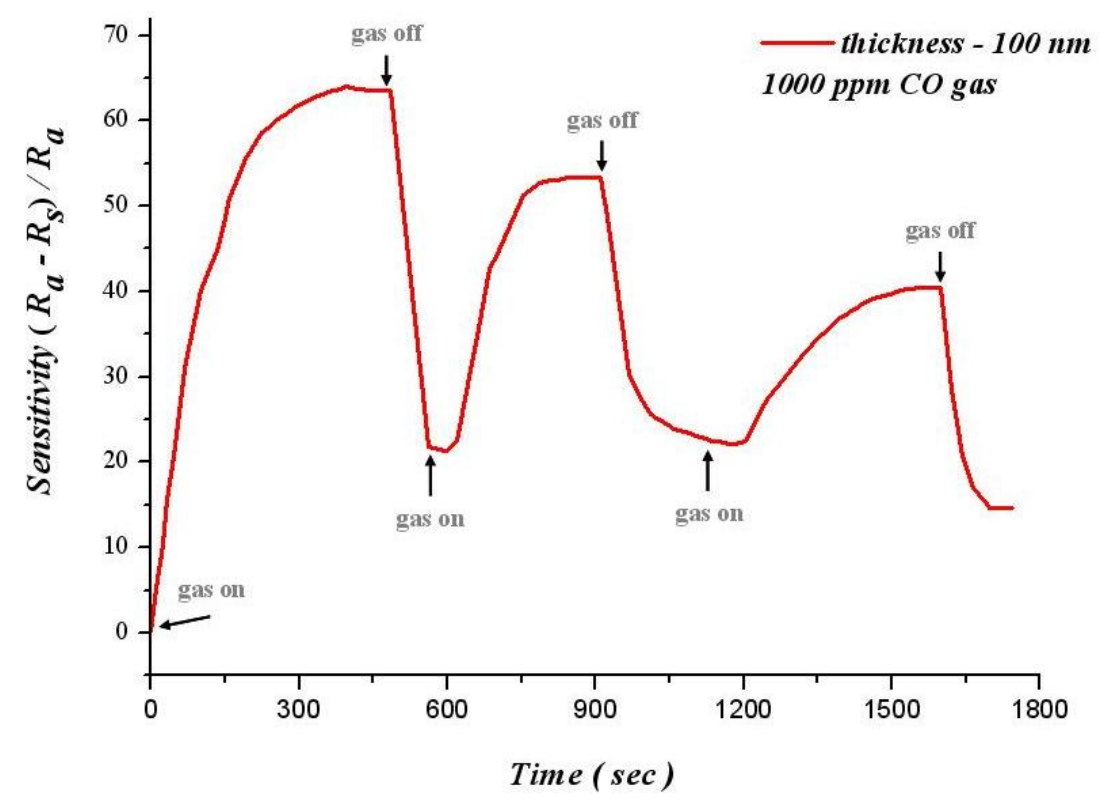

Figure 12. Stability testing in $1,000 \mathrm{ppm}$ of $\mathrm{CO}\left(\mathrm{T}=270^{\circ} \mathrm{C}\right)$.

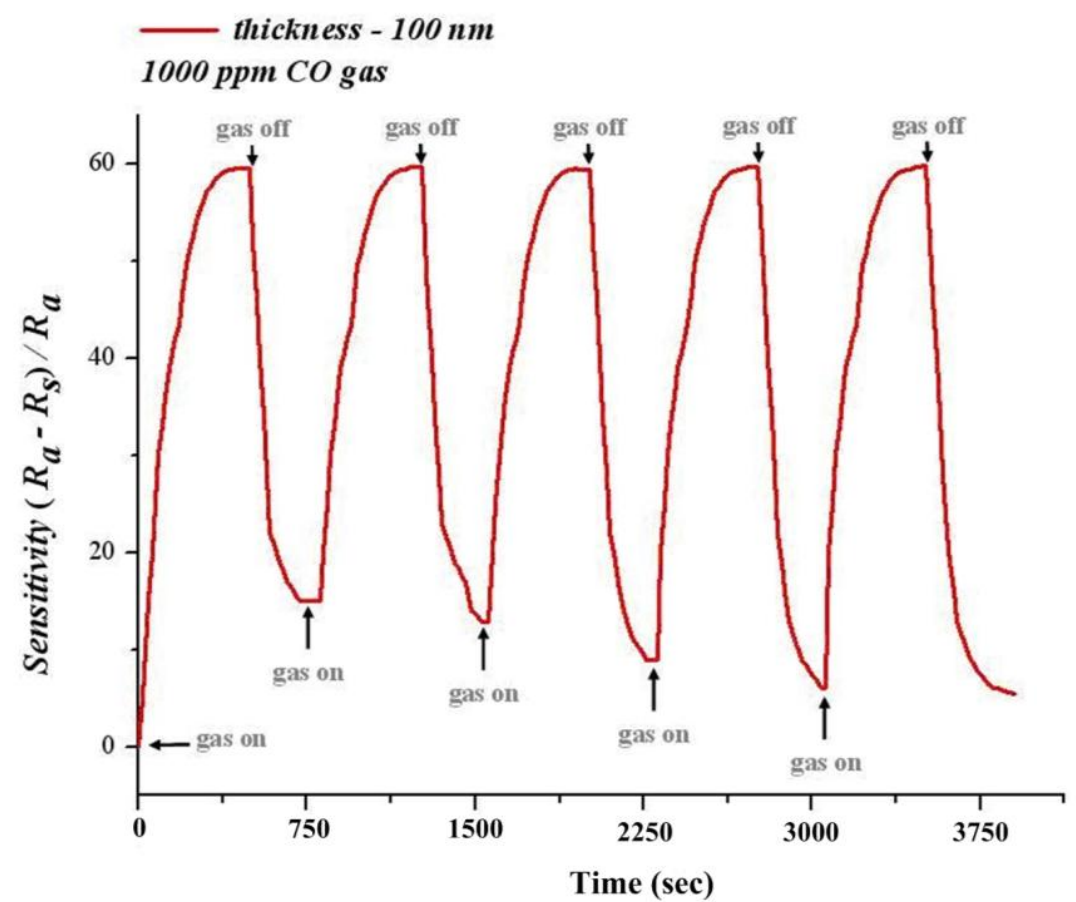


Figure 13. Testing for various $\mathrm{CO}$ concentrations $\left(270{ }^{\circ} \mathrm{C}\right)$.

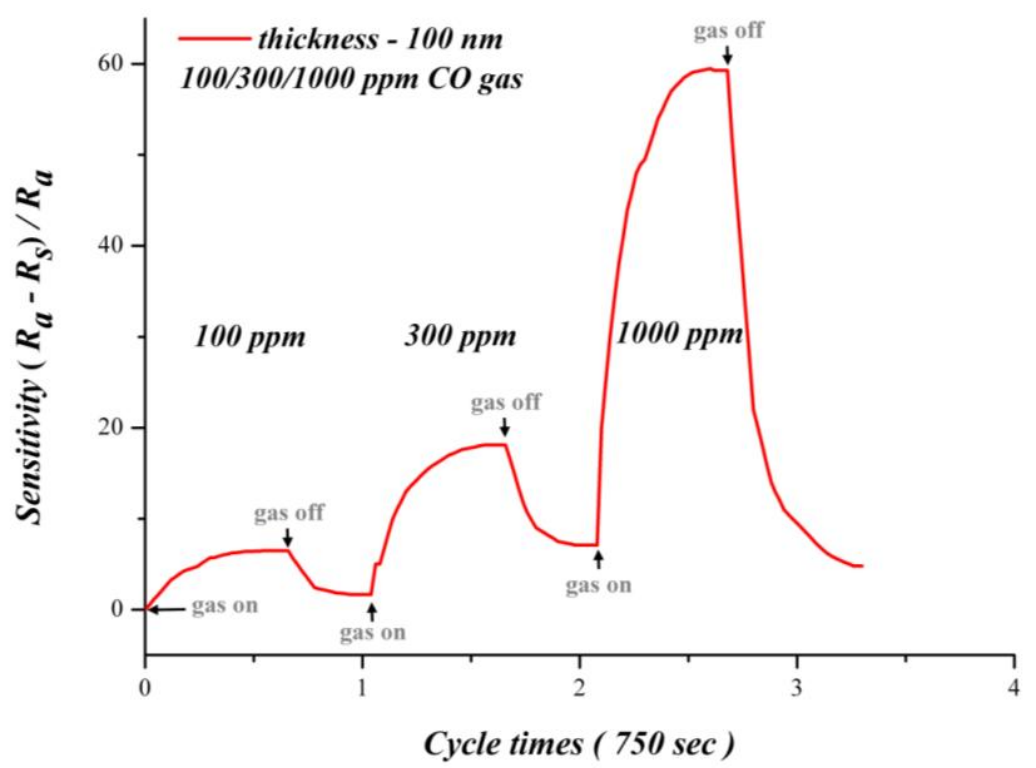

\subsection{Effect of Heat Treatment on Thin Film Sensitive Characteristics}

Figure 14 shows $100 \mathrm{~nm}$ of as-deposited film processing heat treatment in oxygen and vacuum separately at $400{ }^{\circ} \mathrm{C}$ for 1 hour, as well as dynamic analysis of sensitivity at $250{ }^{\circ} \mathrm{C}, 1,000 \mathrm{ppm}$ of $\mathrm{CO}$. The thin film has not been heat treated with the highest sensitivity of $54.11 \%$ after infusing CO for 350 seconds. Additionally, the thin film after heat treatment is thinner than before heat treatment. We can infer that the thin film after heat treatment becomes more flat, leading to a decreased adsorption of oxygen. Consequently, the sensitivity of thin film after heat treatment is lower than that before heat treatment. Although lower after heat treatment, sensitivity of thin films increases steadily before saturation.

Figure 14. Analysis of different heat treatments to $\mathrm{CO}$ sensitivity.

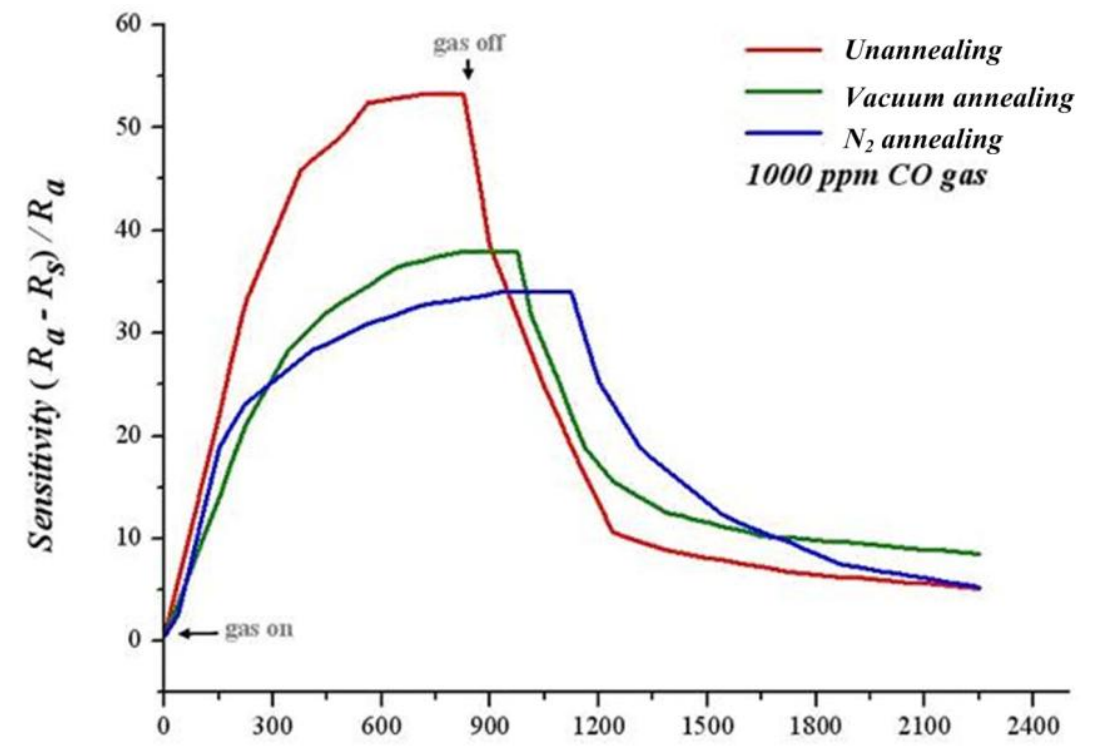

Time (sec) 


\subsection{Effect of Catalyst on Response Time}

Figure 15 shows different sputtering times for platinum sludging on $\mathrm{SnO}_{2}$ thin film, the relation between sensitivity and operating temperature in $1,000 \mathrm{ppm}$ of $\mathrm{CO}$. When sputtering $\mathrm{Pt}$ for 15 seconds, 30 seconds and 45 seconds, our results indicate that when the temperature approaches $250{ }^{\circ} \mathrm{C}$, sensitivity decreases with a rising temperature. This temperature may be related to a lower catalyst activity. When the temperature increases to $300{ }^{\circ} \mathrm{C}$, sensitivity decreases due to the difficulty to proceed with the reaction when the temperature exceeds a critical temperature. The optimum sensitivity for adding a catalyst ranges from $200{ }^{\circ} \mathrm{C}$ to $250{ }^{\circ} \mathrm{C}$. Moreover, sensitivity of sputtering 45 seconds does not increase when adding more catalyst because platinum quarantines the $\mathrm{CO}$ and $\mathrm{SnO}_{2}$ thin films.

Moreover, according to Figure 16 , the best sensitivity at $300{ }^{\circ} \mathrm{C}$ of sputtering $\mathrm{Au}$ for 15 seconds, 30 seconds and 45 seconds are $68.3 \%, 61.3 \%$ and $54.2 \%$. The sensitivity of sputtering $\mathrm{Au}$ for 15 seconds at $150{ }^{\circ} \mathrm{C}$ is $45.74 \%$, i.e., significantly higher than the thin film that does not have gold added (13.33\%). This finding suggests that adding gold can significantly increase sensitivity and response time.

According to previous studies [11-14], the oxidation activity of gold is significantly higher than that of platinum, ruthenium and palladium; in addition, the catalyst life is also longer. This finding explains why sputtering $\mathrm{Au}$ gives a better response time and sensitivity than sputtering $\mathrm{Pt}$, and sensitivity of gold increasing with a rising temperature.

Figure 15. Relation between temperature and sensitivity during various platinum deposition times.

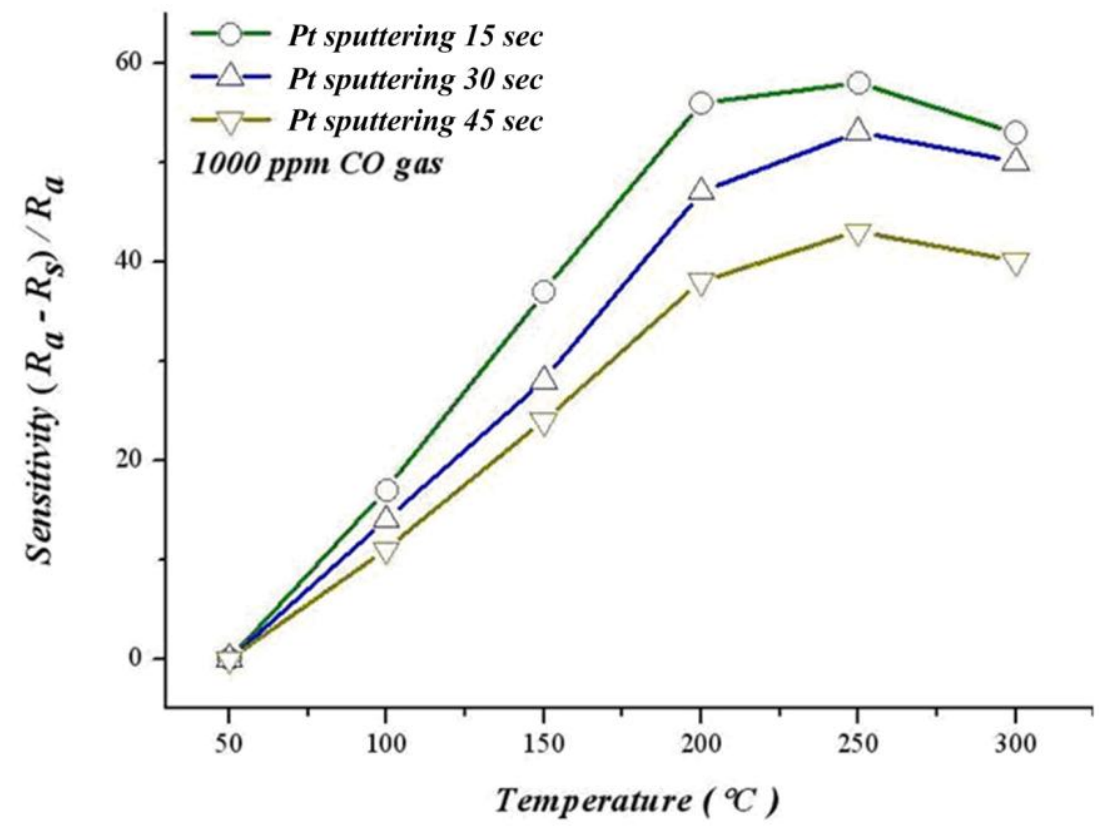


Figure 16. Relation between temperature and sensitivity during different gold deposition intervals.

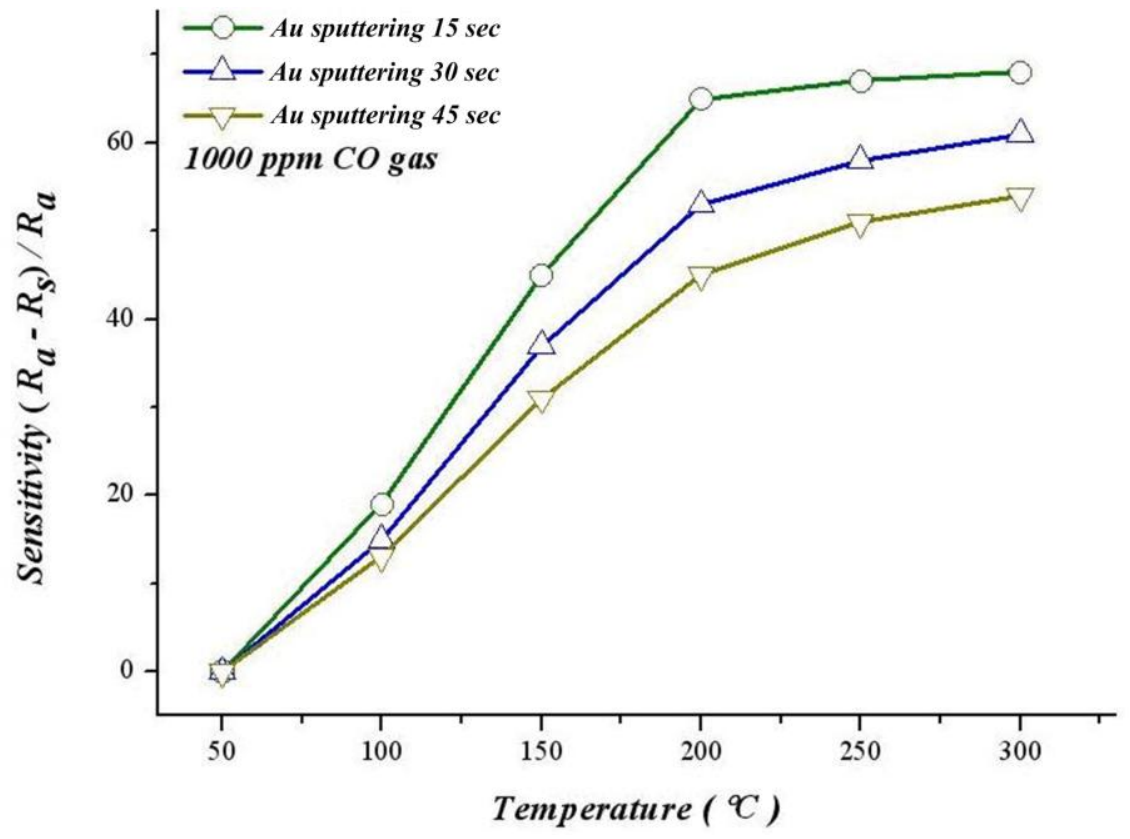

\section{Conclusions}

This study describes the successful fabrication of a micro CO sensor with MEMS technology, in which gas sensitivity influences $\mathrm{CO}$. Additionally, the micro $\mathrm{CO}$ sensor could be embedded into a micro reformer to evaluate the $\mathrm{CO}$ concentration in each part of the micro reformer in the future, demonstrating the inner reactions of the micro reformer in depth with immediate detection capability.

\section{Acknowledgements}

This work was accomplished with much needed support and the authors would like to thank the financial support of this research from the Aim for the Top university project of the Ministry of Education of the R.O.C. and YZU Fuel Cell Center through the grant No. 217019 and National Science Council of R.O.C. through the grant NSC 98-2627-M-155-003. The authors also like to thank Shuo Jen Lee, Chia Chieh Shen, Chuin Tih Yeh, Shih Hung Chan, Kuen Song Lin, S.D. Lin, Ay Su, Fangbor Weng, Guo Bin Jung of Yuan Ze University for their valuable advice and assistance in the experiments. In addition, we would like to thank the YZU Fuel Cell Center and NENS Common Lab, for providing access to their research facilities.

\section{References}

1. Fukui, K.; Nakane, M. CO gas sensor based on $\mathrm{Au}-\mathrm{La}_{2} \mathrm{O}_{3}$ loaded $\mathrm{SnO}_{2}$ ceramic. Sens. Actuat. $B$ 1995, 25, 486-490.

2. Williams, E.W.; Keeling, A.G. Thick film tin oxide sensors for detecting carbon monoxide at room temperature. J. Mater. Sci. Mater. Electron. 1998, 9, 51-54. 
3. Horrillo, M.C.; Gutierrez, J.; Ares, L.; Robla, J.I.; Sayago, I.; Getino, J.; Agapito, J.A. The influence of the tin oxide deposition technique on the sensitivity to CO. Sens. Actuat. B 1995, 25, 507-511.

4. Habibzadeh, S.; Khodadadi, A.A.; Mortazavi, Y. CO and ethanol dual selective sensor of $\mathrm{Sm}_{2} \mathrm{O}_{3}$-doped $\mathrm{SnO}_{2}$ nanoparticles synthesized by microwave-induced combustion. Sens. Actuat. B 2010, 144, 131-138.

5. Izu, N.; Nishizaki, S.; Itoh, T.; Nishibori, M.; Shin, W.; Matsubara, I. Gas response, response time and selectivity of a resistive $\mathrm{CO}$ sensor based on two connected $\mathrm{CeO}_{2}$ thick films with various particle sizes. Sens. Actuat. B 2009, 136, 364-370.

6. Pijolat, C.; Tournier, G.; Viricelle, J.P. Detection of $\mathrm{CO}$ in $\mathrm{H}_{2}$-rich gases with a samarium doped ceria (SDC) sensor for fuel cell applications. Sens. Actuat. B 2009, 141, 7-12.

7. Wang, C.T.; Chen, M.T. Vanadium-promoted tin oxide semiconductor carbon monoxide gas sensors. Sens. Actuat. B 2010, 150, 360-366.

8. Joshi, R.K.; Weber, J.E.; Hu, Q.; Johnson, B.; Zimmer, J.W.; Kumar, A. Carbon monoxide sensing at room temperature via electron donation in boron doped diamond films. Sens. Actuat. B 2010, 145, 527-532.

9. Chen, J.; Hangauer, A.; Strzoda, R.; Fleischer, M.; Amann, M.C. Miniaturized laser spectroscopic $\mathrm{CO}$ sensor for industrial and safety applications. In Proceedings of the Eurosensors XXIII conference, Lausanne, Switzerland, 6-9 September 2009; pp. 1383-1386.

10. Pink, H.; Treitinger, L.; Vite, L. Preparation of fast detecting $\mathrm{SnO}_{2}$ gas sensor. Jpn. J. Appl. Phys. 1980, 19, 513-517.

11. Oliaee, S.N.; Khodadadi, A.; Mortazavi, Y.; Alipour, S. Highly selective Pt/SnO ${ }_{2}$ sensor to propane or methane in presence of $\mathrm{CO}$ and ethanol, using gold nanoparticles on $\mathrm{Fe}_{2} \mathrm{O}_{3}$ catalytic filter. Sens. Actuat. B 2010, 147, 400-405.

12. Gardner, S.D.; Hoflund, G.B.; Upchurch, B.T.; Schryer, D.R.; Kielin, E.J.; Schryer, J. Comparison of the performance characteristics of $\mathrm{Pt} / \mathrm{SnO}_{\mathrm{x}}$ and $\mathrm{Au} / \mathrm{MnO}_{\mathrm{x}}$ catalysts for low-temperature $\mathrm{CO}$ oxidation. J. Catal. 1991, 129, 114-120.

13. Gardner, S.D.; Hoflund, G.B.; Upchurch, B.T.; Schryer, D.R.; Kielin, E.J. Au/MnO $\mathrm{M}_{\mathrm{x}}$ catalystic performance characteristics for low-temperature carbon monoxide oxidation. Appl. Catal. B 1995, $6,117-126$.

14. Hutchings, G.J. Catalysis: A golden future. Gold Bull. 1996, 29, 123-130.

(C) 2010 by the authors; licensee MDPI, Basel, Switzerland. This article is an open access article distributed under the terms and conditions of the Creative Commons Attribution license (http://creativecommons.org/licenses/by/3.0/). 